\title{
Structural transitions of epitaxial ceria films on $\mathrm{Si}(111)$
}

\author{
H. Wilkens, ${ }^{a}$ O. Schuckmann, ${ }^{a}$ R. Oelke, ${ }^{a}$ S. Gevers, ${ }^{a}$ M. Reichling, ${ }^{a}$ A. Schaefer, ${ }^{b}$ M. Bäumer, ${ }^{b}$ M. H. \\ Zoellner, ${ }^{c}$ G. Niu, ${ }^{c}$ T. Schroeder, ${ }^{c, d}$ and J. Wollschläger ${ }^{* a}$
}

\author{
Received Xth $X X X X X X X X X X 20 X X$, Accepted Xth $X X X X X X X X X 20 X X$ \\ First published on the web Xth $X X X X X X X X X X 200 X$ \\ DOI: 10.1039/b000000x
}

The structural changes of a (111) oriented $\mathrm{CeO}_{2}$ film grown on a hex- $\mathrm{Pr}_{2} \mathrm{O}_{3}(0001) / \mathrm{Si}(111)$ system due to post deposition annealing are investigated. X-ray photoelectron spectroscopy measurements revealing the near surface stoichiometry show that the film reduces continuously upon extended heat treatment. The film is not homogeneously reduced since several coexisting crystalline ceria phases are stabilized due to subsequent annealing at different temperatures as revealed by high resolution low energy electron diffraction and x-ray diffraction. The electron diffraction measurements show that after annealing at $660^{\circ} \mathrm{C}$ the l-phase $\left(\mathrm{Ce}_{7} \mathrm{O}_{12}\right)$ is formed at the surface which exhibits a $(\sqrt{7} \times \sqrt{7}) \mathrm{R} 19.1^{\circ}$ structure. Furthermore, a $(\sqrt{27} \times \sqrt{27}) \mathrm{R} 30^{\circ}$ surface structure with a stoichiometry close to $\mathrm{Ce}_{2} \mathrm{O}_{3}$ is stabilized after annealing at $860^{\circ} \mathrm{C}$ which can not be attributed to any bulk phase of ceria stable at room temperature. In addition, it is shown that the fully reduced ceria $\left(\mathrm{Ce}_{2} \mathrm{O}_{3}\right)$ film exhibits a bixbyite structure. Polycrystalline silicate $\left(\mathrm{CeSi}_{x} \mathrm{O}_{y}\right)$ and crystalline silicide $\left(\mathrm{CeSi}_{1.67}\right)$ are formed at $850^{\circ} \mathrm{C}$ and detected at the surface after annealing above $900^{\circ} \mathrm{C}$.

\section{Introduction}

Ceria plays a key role in the field of catalysis. For instance, ceria is used in several reactions ${ }^{1}$ like the three-way automotive exhaust catalysis ${ }^{2}$ or the generation of hydrogen ${ }^{3}$. The catalytic activity is strongly influenced by oxygen vacancies especially at the surface. Hence, it is necessary to control the density and distribution of oxygen vacancies to build ceria based catalysts with tailored reactivity and selectivity. For obtaining a deep insight into the complex chemical reactions a single crystalline film with (111) orientation can be used as a ceria model catalyst where the atomic structure of surface and sub-surface oxygen vacancies is well known ${ }^{4}$. Using a two dimensional film instead of a polycrystalline three dimensional structure facilitates the use of variety a of surface science techniques $^{5-7}$ since these films exhibit a well-defined crystalline structures ${ }^{8}$ and surface morphology 9 .

Here, silicon with (111) orientation is a well-suited substrate since ceria exhibits a small lattice mismatch $(-0.35 \%)$ with respect to $\mathrm{Si}(111)^{10-12}$. Furthermore, ultrathin ceria films on $\mathrm{Si}$ substrates are very attractive since ceria is well-known as insulating buffer layer for functional oxide integration in the field of micro- and nanoelectronics due to its high di-

\footnotetext{
a Fachbereich Physik, Universität Osnabrück, Barbarastr. 7, 49076 Osnabrück, Germany. E-mail: joachim.wollschlaeger@uos.de

${ }^{b}$ Institute of Applied and Physical Chemistry, University of Bremen, Leobener Str. NW2, 28359 Bremen, Germany.

${ }^{c}$ IHP, Im Technologiepark 25, 15236 Frankfurt(Oder), Germany.

${ }^{d}$ BTU Cottbus, Institute of Physics, Konrad-Zuse-Str.1, 03046 Cottbus, Germany.
}

electric constant $(\approx 26)$. In addition, recent studies reveal the existence of room temperature ferromagnetism (RTFM) in doped and reduced ceria giving the opportunity of combing future spintronic devices with the existing silicon based technology ${ }^{13-18}$. Oxygen vacancies have a strong influence on the magnetic properties in reduced ceria. However, the origin of this magnetism has not unambiguously been resolved up to now. The controlled generation of oxygen vacancies with long range order, as presented in this study, can be used to examine the role of oxygen vacancies in future studies elucidating the magnetic properties in more detail.

For bulk materials, the cerium - oxygen phase diagram exhibits several intermediate phases ${ }^{19-21}$ between the highest $\left(\mathrm{CeO}_{2}\right)$ and lowest oxidation state $\left(\mathrm{Ce}_{2} \mathrm{O}_{3}\right)$. It is still a challenge to stabilize intermediate phases for thin films with high structural control. Recently, we have demonstrated that it is possible to stabilize the surface of the ceria $l$-phase $\left(\mathrm{Ce}_{7} \mathrm{O}_{12}\right)$ on a hex- $\mathrm{Pr}_{2} \mathrm{O}_{3}(0001) / \mathrm{Si}(111)$ system due to the reduction of a $\mathrm{CeO}_{2}$ (111) film. ${ }^{22}$ However, it is not yet clear whether the entire film is reduced to the $\mathrm{Ce}_{7} \mathrm{O}_{12}$ structure and whether it is possible to stabilize other intermediate phases. Therefore, we conduct a detailed study of the structural changes of a 250 $\mathrm{nm} \mathrm{CeO} 2$ (111) film grown on a hex- $\mathrm{Pr}_{2} \mathrm{O}_{3}(0001) / \mathrm{Si}(111)$ system ${ }^{8}$ addressing, both, the surface and the bulk stoichiometry and crystal structure for different post deposition annealing (PDA) temperatures ${ }^{9}$. The oxidation state of the surface is determined via X-ray photoelectron spectroscopy (XPS) while experiments with high resolution low energy electron diffraction combined with spot profile analysis (SPA-LEED) are performed to determine the changes in the atomic structure at 
the surface. In addition, transitions of the crystal structure throughout the film are investigated with synchrotron based in-situ X-ray diffraction (XRD) measurements.

\section{Experiment}



Fig. 1 Schematic drawing of the investigated system. XPS and LEED are used to probe the near surface region while changes of the entire structure are studied by XRD.

Ceria films are grown via molecular beam epitaxy (MBE) on boron doped $4^{\prime \prime} \operatorname{Si}(111)$ wafers $(\sigma=5-15 \Omega \mathrm{cm})$ which are cleaned and hydrogen terminated according to the recipe described in Ref. ${ }^{23}$. After loading the wafer into an ultrahigh vacuum (UHV) chamber (base pressure $10^{-10} \mathrm{mbar}$ ) and annealing at $700^{\circ} \mathrm{C}$ for $5 \mathrm{~min}$, the $\operatorname{Si}(111)(7 \times 7)$ surface reconstruction is obtained. An ultrathin hex- $\operatorname{Pr}_{2} \mathrm{O}_{3}(0001)$ buffer layer is grown at a substrate temperature of $625^{\circ} \mathrm{C}$ and a deposition rate of $3 \mathrm{~nm} / \mathrm{min} .{ }^{24}$ The growth is monitored via reflection high-energy electron diffraction (RHEED) and the deposition is stopped after complete coverage of the substrate is reached ( thickness $\approx 3 \mathrm{~nm}$ ). Afterwards, a cub-CeO $\mathrm{C}_{2}(111)$ film (thickness $\approx 250 \mathrm{~nm}$ ) is deposited using the same substrate temperature and deposition rate. The $\mathrm{CeO}_{2}$ (111) film exhibits the fluorite crystal structure and a high crystalline quality as confirmed by ex-situ XRD (data not shown).

The surface characterization is performed in two different UHV chambers (base pressure $10^{-10}$ mbar both). The first chamber is equipped with a SPA-LEED system and the sample are annealed via resistive heating of the Si substrate. XPS measurements with $\mathrm{Al} \mathrm{K}_{\alpha}$ radiation $(1486.6 \mathrm{eV}$ ) are performed in a second chamber where the surface structure is controlled with conventional LEED while the samples are annealed via filament heating. For both experimental setups, samples are successively annealed for $30 \mathrm{~min}$ and the temperature is controlled with an infrared (IR) pyrometer. After each PDA step the samples are cooled to room temperature (RT) to perform the measurements. When resistive heating is used, samples cool to room temperature almost immediately (cooling rate $\approx 500^{\circ} \mathrm{C} / \mathrm{min}$ ). If annealed via filament the sample cooling takes several hours (cooling rate $\approx 5^{\circ} \mathrm{C} / \mathrm{min}$ ) due to the large heat capacity of the sample holder.

The exposure of praseodymia films to an oxygen plasma has proven to be a superior method to gain high quality praseodymium dioxide $\left(\mathrm{PrO}_{2}\right)$ surfaces ${ }^{26}$ and here we transfer this concept to ceria films. Hence, prior to the SPA-LEED and XPS experiments, samples are transfered to an in-situ plasma chamber (base pressure $10^{-7} \mathrm{mbar}$ ) and exposed to an oxygen microwave plasma $(2.45 \mathrm{GHz})$ for 15 min to clean the surface and to reduce the number of oxygen vacancies at the surface. The plasma parameters are $80 \mathrm{sccm}$ gas flow, 0.26 mbar oxygen pressure and $360 \mathrm{~W}$ power. Due to this treatment, the overall intensity of the XP spectra increases and the previously present small carbon $1 \mathrm{~s}$ signal $\left(\mathrm{E}_{\mathrm{B}}=284 \mathrm{eV}\right)$ due to carbon contaminations vanishes (data not shown). Furthermore, in the electron diffraction measurements the diffuse background intensity is drastically reduced and strong charging effects appear indicating the high quality of the film. Hence, oxygen plasma treatment is a suitable method for cleaning and improving the crystalline quality of $\mathrm{CeO}_{2}$ films.

For the structural characterization of the entire film, untreated samples are investigated with in-situ x-ray diffraction (XRD) measurements carried out in a modified version of the high vacuum $(\mathrm{HV})$ reaction chamber (base pressure $10^{-8}$ mbar) presented in Ref. ${ }^{25}$. The heating stage has been modified to enable resistive heating and an IR pyrometer was added for temperature control. The HV reaction chamber was mounted on a six-circle diffractometer at beamline W1 at DESY (Hamburg, Germany) facilitating diffraction studies with a photon energy of $10.5 \mathrm{keV}$. All measurements are performed at RT.

A schematic drawing of the investigated system is shown in Fig. 1.

\section{Results}

\subsection{XPS}

We determine the stoichiometry of the ceria surface after successive annealing cycles at different temperatures via XPS. The different oxidation states of ceria have extensively been studied by XPS in the past ${ }^{27-30}$. Factor analysis studies have shown that the reduction process of ceria can be described by the two components of $\mathrm{Ce}^{3+}$ and $\mathrm{Ce}^{4+} \cdot 31-33$ Therefore, the oxidation state of the surface can be determined with high accuracy using a superposition of $\mathrm{Ce} 3 \mathrm{~d}$ spectra of both $\mathrm{Ce}_{2} \mathrm{O}_{3}$ and $\mathrm{CeO}_{2}$ since these spectra solely containing $\mathrm{Ce}^{3+}$ and $\mathrm{Ce}^{4+}$ cations, respectively. The plasma treated sample is used as the $\mathrm{CeO}_{2}$ reference spectrum while the $\mathrm{Ce}_{2} \mathrm{O}_{3}$ reference spectrum is obtained after annealing the sample at $890^{\circ} \mathrm{C}$ with respective results shown in Fig. 2. 


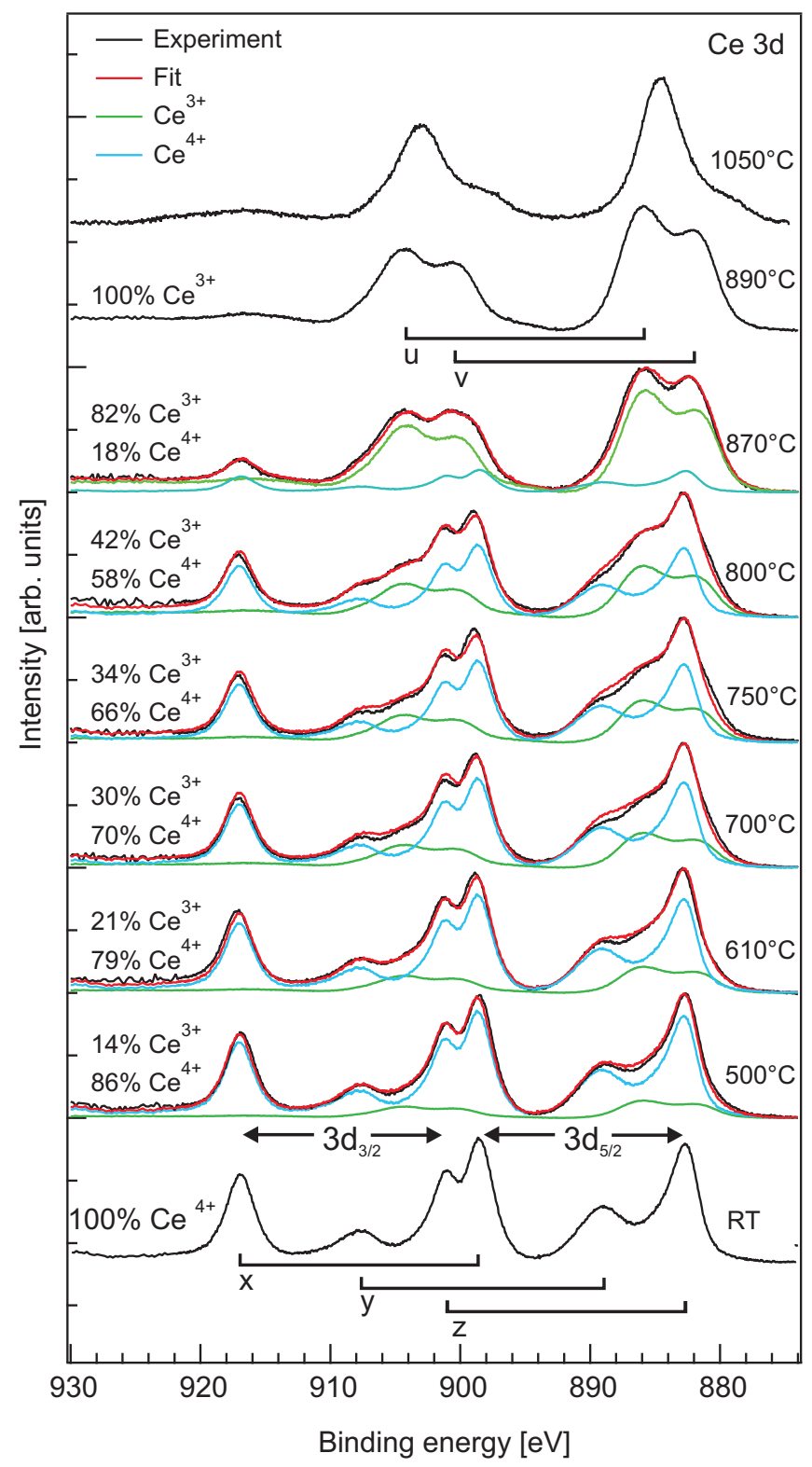

Fig. 2 XP spectra of the Ce $3 \mathrm{~d}$ region. The area underneath the peaks is normalized to unity after a Shirley background is subtracted. The $\mathrm{CeO}_{2}$ spectrum measured on the untreated sample consists of three peaks $(x, y, z)$ in each $3 d_{5 / 2}$ and $3 d_{3 / 2}$ component. All cations have the $\mathrm{Ce}^{4+}$ valence state. The surface near region is fully reduced to $\mathrm{Ce}_{2} \mathrm{O}_{3}$ after annealing at $890^{\circ} \mathrm{C}$ where all cations have the $\mathrm{Ce}^{3+}$ valence state. The spectrum consist of two peaks $(u, v)$ in each $3 d_{5 / 2}$ and $3 d_{3 / 2}$ component. The determination of the $\mathrm{Ce}^{3+} / \mathrm{Ce}^{4+}$ ratio of the intermediate states was done by fitting the spectra with a weighted linear combination of the $\mathrm{CeO}_{2}$ and $\mathrm{Ce}_{2} \mathrm{O}_{3}$ spectra. After annealing at $1050^{\circ} \mathrm{C}$ the peaks $\mathrm{u}$ and $\mathrm{v}$ shift $\approx 1.2 \mathrm{eV}$ and $\approx 2.8 \mathrm{eV}$ to lower binding energies due to silicide or silicate formation.

In the latter case, we assume a completely reduced film since LEED measurements show the $(4 \times 4)$ structure related to expected bixbyite cub- $\mathrm{Ce}_{2} \mathrm{O}_{3}$ phase (cf. Fig. 6) while silicide is formed at higher temperatures as further discussed in the following. Furthermore, these reference spectra are in very good agreement with previously calculated spectra by Kotani et al. ${ }^{35}$.

Fig. 2 shows a series of Ce $3 \mathrm{~d}$ XP spectra with the corresponding fits after successive annealing cycles at different temperatures. Prior to the fitting, a Shirley background is subtracted and the area underneath the peaks is normalized to unity. The fits are in very good agreement with the measured spectra allowing a determination of the $\mathrm{Ce}^{3+} / \mathrm{Ce}^{4+}$ ratio with an accuracy of $3 \%$. The spin-orbit splitting in all Ce $3 \mathrm{~d}$ spectra attributed to ceria is $\approx 18 \mathrm{eV}$.

In the following, the origin and nomenclature of the peaks appearing in the $3 \mathrm{~d}$ spectra presented in Fig. 2 is briefly introduced according to Kotani's theory. Valence band holes and core holes are denoted with $\underline{\mathrm{v}}$ and $\underline{\mathrm{c}}$, respectively. The ground state of $\mathrm{CeO}_{2}$ consists of the hybridization of the $4 \mathrm{f}^{0}$ and $4 \mathrm{f}^{1} \underline{\mathrm{v}}$ configuration according to Kotani's theory which leads to three final states $(x, y, z)$ in each of the $3 d_{5 / 2}$ and $3 d_{3 / 2}$ components. The peaks labeled with $\mathrm{x}$ and $\mathrm{y}$ correspond to the bonding and antibonding final states of the strongly hybridized $4 \mathrm{f}^{1} \underline{\mathrm{v}} \underline{\mathrm{c}}$ and $4 \mathrm{f}^{2} \underline{\mathrm{v}}^{2} \underline{\mathrm{c}}$ configurations while the peak labeled with $\mathrm{z}$ corresponds to the pure $4 \mathrm{f}^{0} \mathrm{c}$ final state. On the contrary, the ground state of $\mathrm{Ce}_{2} \mathrm{O}_{3}$ exhibits only the pure $4 \mathrm{f}^{1}$ configuration, which leads to two final states in each $3 d_{5 / 2}$ and $3 d_{3 / 2}$ component. The peaks labeled with $\mathrm{u}$ and $\mathrm{v}$ in the $\mathrm{Ce} 3 \mathrm{~d}$ spectrum of $\mathrm{Ce}_{2} \mathrm{O}_{3}$ correspond to the bonding and the antibonding final states of the hybridized $4 \mathrm{f}^{1} \underline{\mathrm{c}}$ and $4 \mathrm{f}^{2} \underline{\mathrm{v}} \underline{\mathrm{c}}$ configurations, respectively.

Fig. 3 presents the amount of $\mathrm{Ce}^{3+}$ cations at the surface near region (inelastic mean free path $\lambda \approx 10 \AA$ in $\left.\mathrm{CeO}_{2}\right)^{34}$ of the film after the different annealing steps. The surface reduces continuously as shown by the increasing amount of $\mathrm{Ce}^{3+}$ cations with increasing PDA temperature. Until a PDA temperature of $\approx 800^{\circ} \mathrm{C}$ is reached, the $\mathrm{Ce}^{3+}$ concentration shows only a slight increase. Thereafter, the oxygen release at the surface is drastically increased. After PDA treatments with temperatures higher than $890^{\circ}$ the peaks labeled with u and $\mathrm{v}$ shift $\approx 1.2 \mathrm{eV}$ and $\approx 2.8 \mathrm{eV}$ to lower binding energies, respectively. In addition, the intensity of the peak labeled with $\mathrm{v}$ is strongly reduced. This $3 \mathrm{~d}$ spectrum appears like a metallic cerium spectrum ${ }^{36,37}$ superimposed with a weak $\mathrm{Ce}_{2} \mathrm{O}_{3}$ spectrum $^{35}$.

These results are supported by $\mathrm{Ce} 4 \mathrm{~d}$ spectra presented in Fig. 4 that show the transition from a $\mathrm{CeO}_{2}$ to a $\mathrm{Ce}_{2} \mathrm{O}_{3}$ spectrum with increasing PDA temperature. The measurements of the untreated and at $890^{\circ} \mathrm{C}$ annealed sample are in good agreement with the spectra of $4 \mathrm{~d} \mathrm{CeO}_{2}$ and $\mathrm{Ce}_{2} \mathrm{O}_{3}$ calculated by Kotani et al. ${ }^{35}$, respectively. The $4 \mathrm{~d}$ spectra are only slightly separated in a $4 d_{5 / 2}$ and $4 d_{3 / 2}$ component since the spin orbit splitting is much weaker than for the $3 \mathrm{~d}$ spectra. Furthermore, 


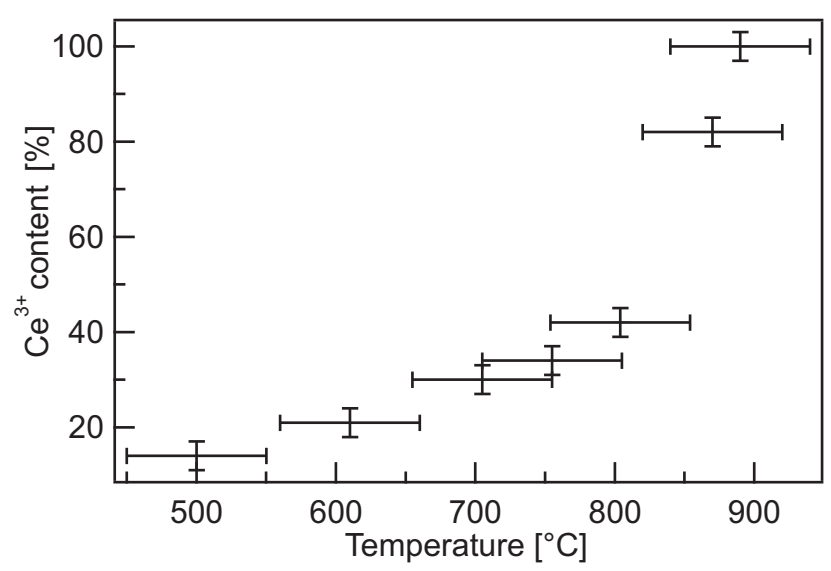

Fig. 3 Plot of the $\mathrm{Ce}^{3+}$ concentration as determined by the analysis of the Ce $3 \mathrm{~d}$ spectra against the annealing temperature. The near surface region is continuously reduced with increasing temperature. After annealing at temperatures above $800^{\circ} \mathrm{C}$, the $\mathrm{Ce}^{3+}$ concentration increases drastically.

this weak splitting cannot be resolved due to the strong overlapping multiplet coupling of the $4 \mathrm{~d}$ and $4 \mathrm{f}$ states. Similar to the $\mathrm{Ce} 3 \mathrm{~d}$ spectra, the intermediate spectra consist of a superposition of the $\mathrm{CeO}_{2}$ and $\mathrm{Ce}_{2} \mathrm{O}_{3}$ spectra. The spectral weight of the characteristic features attributed to the $\mathrm{CeO}_{2} 4 \mathrm{~d}$ spectrum, e. g. the components located at $E_{B}=125.5 \mathrm{eV}$ and $E_{B}$ $=122.2 \mathrm{eV}$, decreases with increasing PDA temperature while the spectral weight of the characteristic features attributed to the $\mathrm{Ce}_{3} \mathrm{O}_{2} 4 \mathrm{~d}$ spectrum increases. Furthermore, a strong Si $2 \mathrm{p}$ signal $\left(\mathrm{E}_{\mathrm{B}}=100.3 \mathrm{eV}\right)$ close to the $\mathrm{Ce} 4 \mathrm{~d}$ signals appears after annealing at $1050^{\circ} \mathrm{C}$ indicating film decomposition by the diffusion of silicon to the surface.

Fig. 5 shows the $\mathrm{O} 1 \mathrm{~s}$ spectra after subsequent annealing at different temperatures. For each measurement the spectrum is normalized to the area of the $\mathrm{Ce} 3 \mathrm{~d}$ peaks. The $\mathrm{O} 1 \mathrm{~s}$ peak attributed to ceria is located at $\mathrm{E}_{\mathrm{B}}=530.2 \mathrm{eV}$ and exhibits a very weak shoulder at $\mathrm{E}_{\mathrm{B}} \approx 532 \mathrm{eV}$. The origin of this shoulder is not clear. Some authors assign this shoulder to isolated oxygen vacancies in the ceria lattice ${ }^{27}$ while others attribute it to surface impurities like hydroxyl groups $28,38,39$.

The intensity of the $\mathrm{O} 1 \mathrm{~s}$ signal attributed to ceria decreases with higher PDA temperatures which is consistent with the increase of the $\mathrm{Ce}^{3+}$ signal in the Ce $3 \mathrm{~d}$ spectra due to oxygen loss during film reduction. However, the weak shoulder is almost unchanged during the PDA treatment. Taking into account our LEED results, which prove that ordered oxygen vacancies emerge at the surface (cf. Sec. 3.2), we conclude that surface contamination is the origin of the shoulder and not oxygen vacancies. On the contrary, the full width at halfmaximum $(\mathrm{FWHM})$ of the $\mathrm{O} 1 \mathrm{~s}$ peak increases from $\approx 1.6$
$\mathrm{eV}$ to $\approx 2.5 \mathrm{eV}$ after annealing above $800^{\circ} \mathrm{C}$. A possible explanation for this effect is a roughening of the surface due to oxygen vacancies caused by the massive release of oxygen in this temperature region (cf. Fig. 3). After annealing above $900^{\circ} \mathrm{C}$ the intensity of the $\mathrm{O} 1 \mathrm{~s}$ peak attributed to ceria is drastically decreased which is in good agreement with the Ce $3 \mathrm{~d}$ spectra and point to the formation of silicide or silicateinstead of oxide. Thus, large areas of the surface are transformed to silicide or silicate and that only a small amount of ceria is left at the surface.

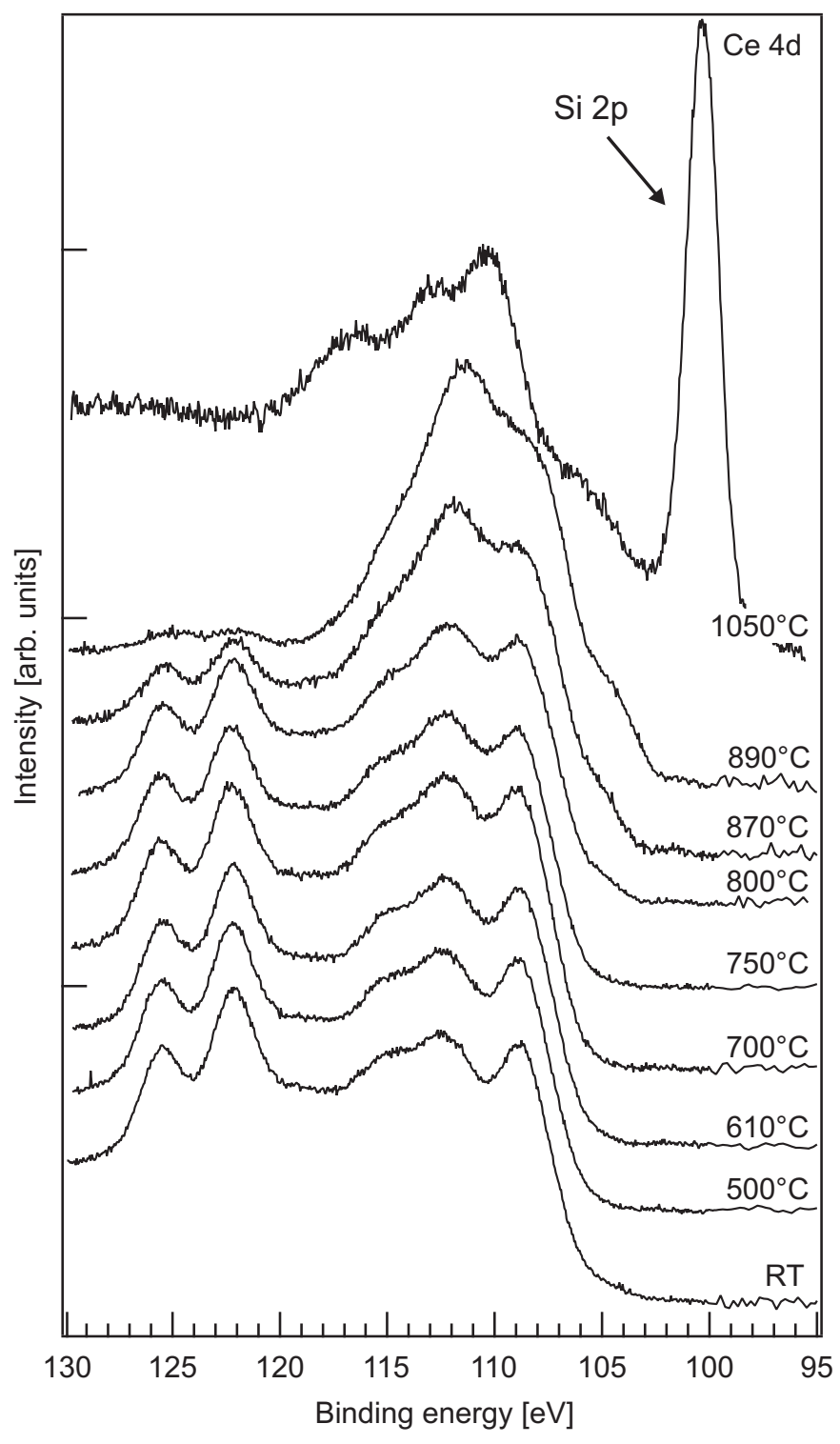

Fig. $4 \mathrm{XP}$ spectra of the $\mathrm{Ce} 4 \mathrm{~d}$ region normalized to the Ce $3 \mathrm{~d}$ signal. After annealing at $1050^{\circ} \mathrm{C}$ a strong Si $2 p$ peak $\left(E_{B}=100.3 \mathrm{eV}\right)$ appears. 


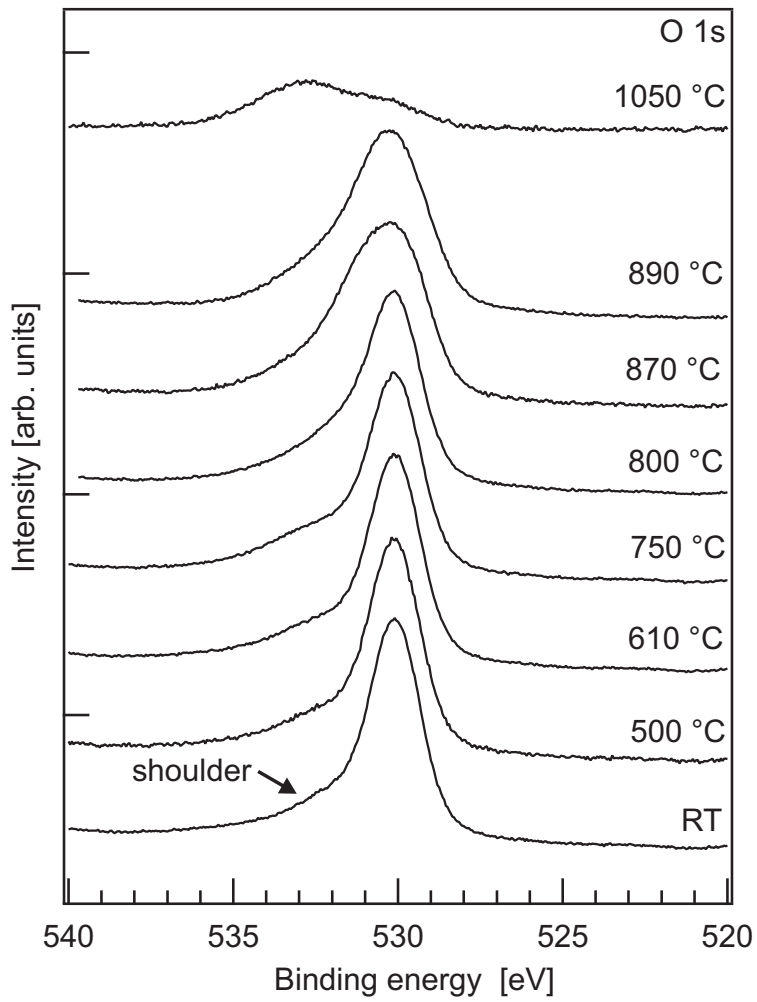

Fig. $5 \mathrm{XP}$ spectra of the $\mathrm{O} 1 \mathrm{~s}$ peak $\left(\mathrm{E}_{\mathrm{B}}=530.2 \mathrm{eV}\right)$ exhibiting a weak shoulder at $\mathrm{E}_{\mathrm{B}} \approx 532 \mathrm{eV}$. The spectra are normalized to the $\mathrm{Ce}$ $3 \mathrm{~d}$ signal. The FWHM of the $\mathrm{O} 1 \mathrm{~s}$ peak increases after annealing above $800^{\circ} \mathrm{C}$. The intensity of the $\mathrm{O} 1 \mathrm{~s}$ peak is drastically reduced after annealing at $1050^{\circ} \mathrm{C}$ and the shoulder shifts to higher binding energies indicating $\mathrm{Si}-\mathrm{O}$ bonds.

\subsection{SPA-LEED}

Structural changes at the surface are investigated with electron diffraction measurements. Fig. 6 shows diffraction patterns of the appearing structures. A hexagonal pattern with a threefold symmetry of the intensity of the first order diffraction spots is visible for the plasma treated sample (cf. Fig. 6 (a)). This threefold intensity distribution is based on the ABC layer stacking sequence along the $\langle 111\rangle$ directions of the cubic fluorite structure of $\mathrm{CeO}_{2}$. Furthermore, at several electron energies, the shape of the main spots becomes triangular indicating the formation of tetrahedral pyramids on the ceria surface (see also Ref. ${ }^{48}$ ).

After annealing at $660^{\circ} \mathrm{C}, \mathrm{a}(\sqrt{7} \times \sqrt{7}) \mathrm{R} 19.1^{\circ}$ superstructure with two mirror domains appears (cf. Fig. 6 (b)). This superstructure can be attributed to the surface structure of the l-phase $\left(\mathrm{Ce}_{7} \mathrm{O}_{12}\right)$ of ceria which is based on ordered oxygen vacancies along the $\langle 111\rangle$ directions in the bulk fluorite $\mathrm{CeO}_{2}$ structure ${ }^{22}$. While the intensity of the fundamental diffraction spots stays almost constant, the intensity of the $(\sqrt{7} \times \sqrt{7}) \mathrm{R} 19.1^{\circ}$ superstructure spots decreases with higher annealing temperatures.

Applying PDA temperatures in the region of $850^{\circ} \mathrm{C}-880^{\circ} \mathrm{C}$ leads to the formation of a $(\sqrt{27} \times \sqrt{27}) \mathrm{R} 30^{\circ}$ structure (cf. Fig. 6 (c)). Note, that there is no sharp transition from the $(\sqrt{7} \times \sqrt{7}) \mathrm{R} 19.1^{\circ}$ to the $(\sqrt{27} \times \sqrt{27}) \mathrm{R} 30^{\circ}$ structure. After annealing at $850^{\circ} \mathrm{C}$ a superposition of these two patterns is measured but the intensity of the $(\sqrt{7} \times \sqrt{7}) \mathrm{R} 19.1^{\circ}$ diffraction peaks is very weak. Thus, both phases coexist for these treatments. Taking into account the XPS results, the $(\sqrt{27} \times \sqrt{27}) \mathrm{R} 30^{\circ}$ structure corresponds to a stoichiometry close to $\mathrm{Ce}_{2} \mathrm{O}_{3}$ with excess oxygen.

After PDA at $880^{\circ} \mathrm{C}$, a weak $(4 \times 4)$ pattern appears $(\mathrm{cf}$. Fig. $6(\mathrm{~d})$ ) that can be attributed to the bixbyite structure of cub- $\mathrm{Ce}_{2} \mathrm{O}_{3}$ similar to cub- $\mathrm{Pr}_{2} \mathrm{O}_{3}(111)$ grown on $\mathrm{Si}(111)^{40,41}$. Fig. 6 (f) compares cross section of the diffraction pattern from the $(4 \times 4)$ bixbyite structure (upper curve) and the $(\sqrt{27} \times \sqrt{27}) \mathrm{R} 30^{\circ}$ structure. These line scans are normalized to the (surface) Brillouin-zone size (BZ) of $\mathrm{CeO}_{2}(111)$ (lateral row distance $\mathrm{a}_{\mathrm{CeO}_{2}}=3.314 \AA$ ).

After annealing above $900^{\circ} \mathrm{C}$, a sharp $(2 \times 1)$ pattern with weak streaks between the fundamental diffraction spots appears (cf. Fig. 6 (e)). This pattern is superimposed with a $(\sqrt{3} \times \sqrt{3}) \mathrm{R} 30^{\circ}$ pattern and has been assigned to different surface phases of cerium silicide ${ }^{42,43}$. In addition, very weak polycrystalline rings become visible at several electron energies (data not shown). These findings are in good agreement with the XPS results since a strong Si $2 p$ signal $\left(E_{B}=100.3\right.$ $\mathrm{eV}$ ) appears when annealing at temperatures above $900^{\circ} \mathrm{C}$ (cf. Fig. 4) indicating the segregation of Si to the surface.

A detailed spot profile analysis is performed after each annealing cycle to get deeper insight of the near surface structure and surface morphology. In the following, $K_{\|}$and $K_{\perp}$ denote the lateral and vertical components of the scattering vector with respect to the sample surface. Cross-sections (line scans) are measured through the (00)-spot along the [112] direction. The data was fitted with two Lorentzian functions, one sharp and intense component for the central diffraction spot and the other for the appearing broad and weak shoulder due to the triangular reflex shape (cf. Fig. 7 (a)).

The first function has its center at $K_{\|}=0$ (central peak), while the lateral position of the shoulder changes with $\mathrm{K}_{\perp}$. This behavior of the shoulder is caused by facets at the film surface $^{44,45}$. The FWHM of the central peak oscillates with $\mathrm{K}_{\perp}$ (cf. Fig. 7 (b)) indicating that flat terraces are separated by atomic steps. These oscillations can be fitted by the function

$$
\operatorname{FWHM}\left(K_{\perp}\right)=100 \% \mathrm{BZ} \frac{a_{\mathrm{CeO}_{2}} \sqrt{2^{2 / 3}-1}}{\pi}\left(\frac{1-\cos \left(d K_{\perp}\right)}{\langle\Gamma\rangle}\right)
$$

according to the model presented in Ref. ${ }^{46,47}$. Here, $d$ denotes the step height and $\langle\Gamma\rangle$ the mean terrace width. Compared 

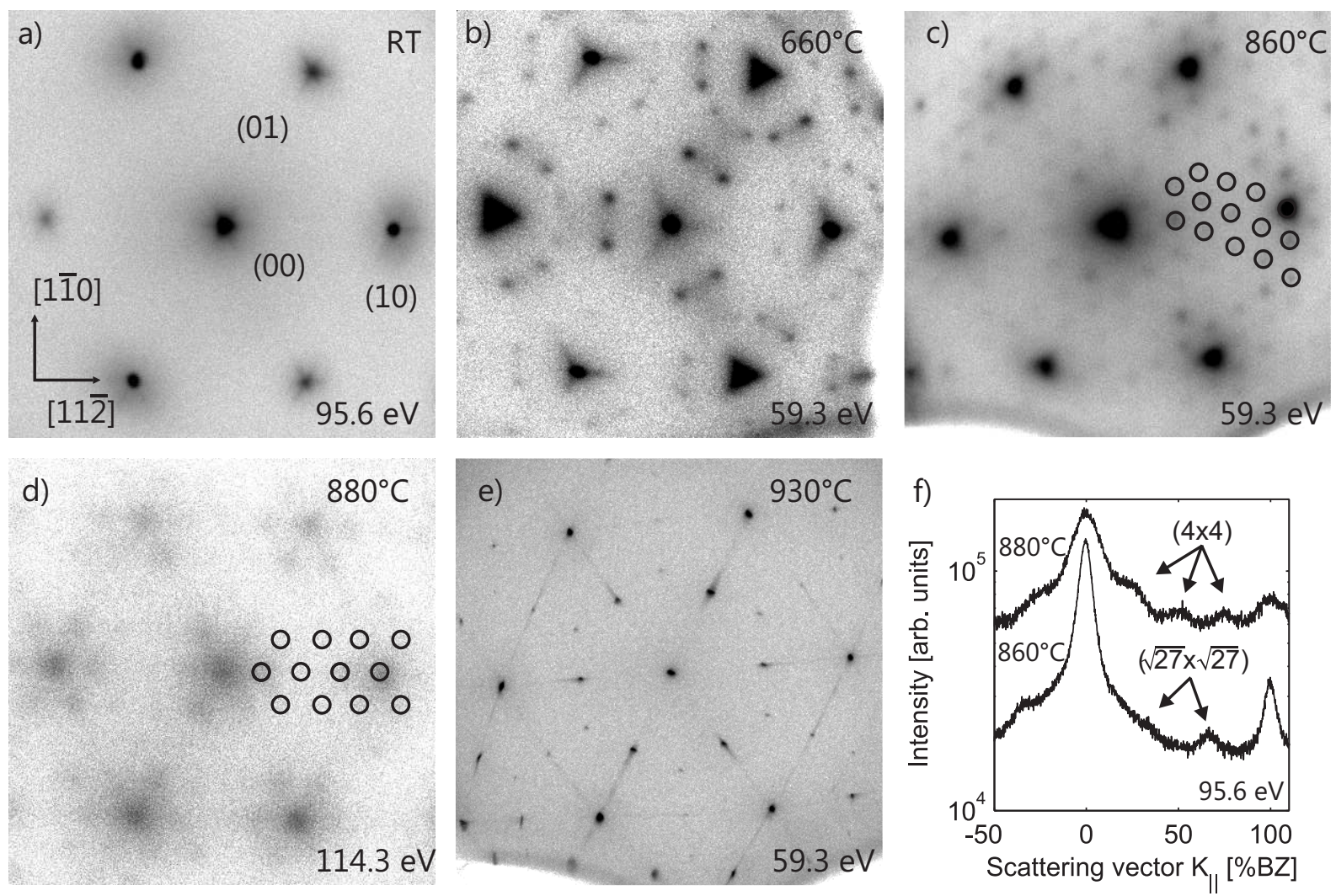

Fig. 6 Two dimensional SPA-LEED pattern of the appearing structures close to Bragg conditions (in-phase) of $\mathrm{CeO}_{2}(111)$. (a) The $(1 \times$ 1) structure of the sample stays unchanged at low and moderate temperatures. (b) At a PDA temperature of $660^{\circ} \mathrm{C}$ a $(\sqrt{7} \times \sqrt{7}) \mathrm{R} 19.1^{\circ}$ superstructure attributed to the $l$-phase $\left(\mathrm{Ce}_{7} \mathrm{O}_{12}\right)$ appears. (c) In the narrow temperature region of $850^{\circ} \mathrm{C}-870^{\circ} \mathrm{C}$ a $(\sqrt{27} \times \sqrt{27}) \mathrm{R} 30^{\circ}$ structure forms. (d) A weak $(4 \times 4)$ structure assigned to the bixbyite phase of $\mathrm{Ce}_{2} \mathrm{O}_{3}$ appears at PDA temperatures of $880^{\circ} \mathrm{C}-890^{\circ} \mathrm{C}$. (e) After annealing above $900^{\circ} \mathrm{C}$, a sharp $(2 \times 1)$ pattern superimposed with a $(\sqrt{3} \times \sqrt{3}) \mathrm{R} 30^{\circ}$ structure appears which can be assigned to cerium silicide. (f) Cross section along the $[11 \overline{2}]$ direction. The $(\sqrt{27} \times \sqrt{27}) \mathrm{R} 30^{\circ}$ and the $(4 \times 4)$ structures show two and three peaks between the fundamental diffraction spots, respectively.

to Ref. ${ }^{46}$ the prefactor $\sqrt{2^{2 / 3}-1}$ is needed to describe the isotropic exponentially decaying 2D correlation.

The spot profile analysis for PDA temperatures up to $660^{\circ} \mathrm{C}$ yields the same results within experimental error (independent of the annealing temperature). An average step height of $d=(3.09 \pm 0.05) \AA$ close to the bulk value of $\mathrm{CeO}_{2}(111)$ crystal plane spacing $\left(c_{\mathrm{CeO}_{2}}=3.124 \AA\right)$ is determined in accordance with recent studies by non-contact atomic force microscopy $^{48}$. Furthermore, the average terrace width $(\langle\Gamma\rangle=$ $(6.0 \pm 0.5) \mathrm{nm})$ does not change significantly in this temperature region. These results are in good agreement with the XRD results described in the following section which also show no change of the bulk structure for low annealing temperatures.

For PDA temperatures above $660^{\circ} \mathrm{C}$, the oscillating part of the FWHM curves is strongly diminished indicating the formation of large terraces beyond the resolution of our instrument. The smoothening of the ceria film surface, however, has also been observed in a NC-AFM study on similar films ${ }^{48}$ with an overall morphology closely resembling that of a (111)surface of bulk ceria. ${ }^{9,49}$

\subsection{XRD results}

Reciprocal space mappings of in-situ XRD measurements, as well as, $(00 L)$ crystal truncation rods (CTRs) after annealing at different temperatures are presented in Fig. 8 and Fig. 9, respectively. The measurements after each annealing step are performed at RT, too. In the following, the subscripts $S$ and $B$ denote surface and bulk coordinates, respectively. The component of the scattering vector $K_{\perp}$ normal to the surface is scaled to reciprocal lattice units (r.l.u.) of the silicon substrate via $L=2 \pi K_{\perp} / c_{\mathrm{Si}}$ where $c_{\mathrm{Si}}=3.136 \AA$ denotes the vertical layer spacing of $\mathrm{Si}(111)$. Thus, the peaks denoted by $(00 L)_{S}$ correspond to the $(L L L)_{B}$ bulk Bragg peaks.

Fig. 8 shows reciprocal space mappings of the specular $(00 L)$-rod close to the $\mathrm{Si}(111)_{B}$ Bragg peak which is equiv- 

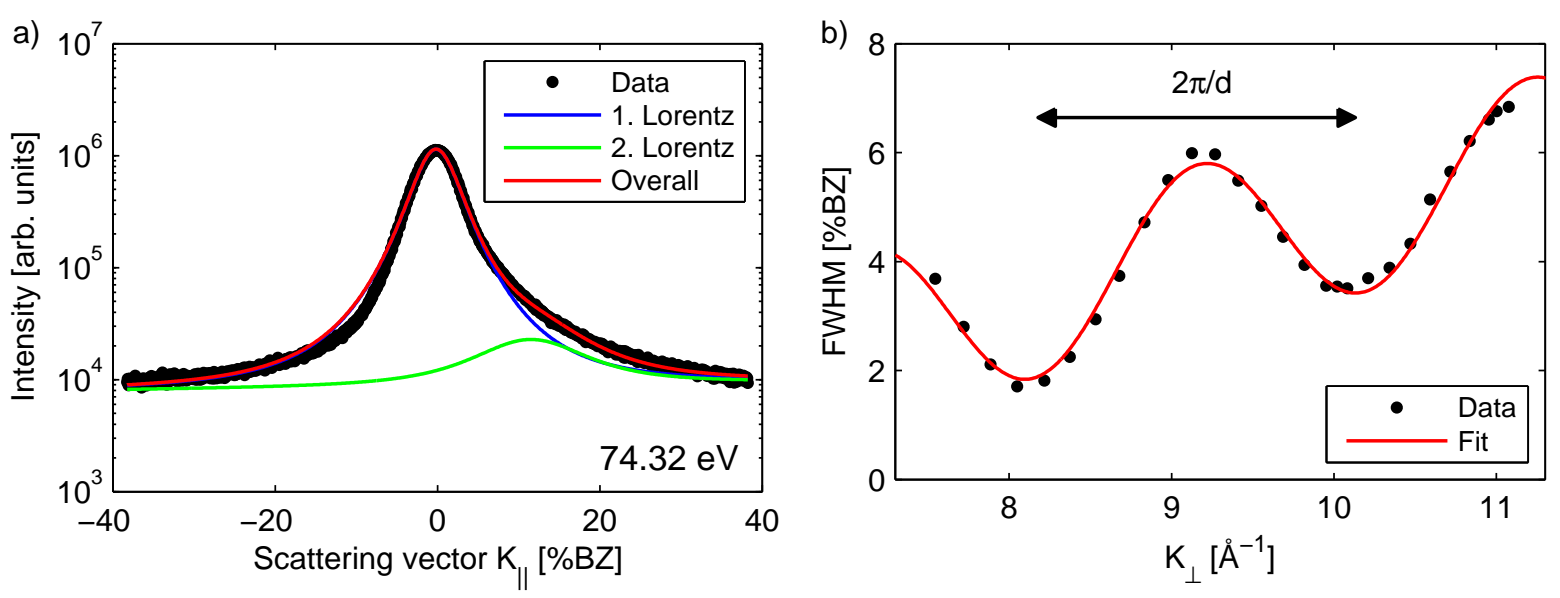

Fig. 7 (a) Cross section in the SPA-LEED pattern along the [112] direction after annealing at $500^{\circ} \mathrm{C}$ for 30 min. The central peak (blue) and the shoulder (green) are fitted with Lorentzian functions. (b) FWHM of the central peak plotted against $K_{\perp}$ after annealing at $500^{\circ} \mathrm{C}$ for 30 min. The fit according to Eq. 1 is in good agreement with the experimental data.

alent to $\mathrm{Si}(001)_{S}$. For the as grown samples, a broad oxide Bragg peak next to the sharp silicon peak is visible at slightly larger $L$ values than $\mathrm{Si}$. This peak can be attributed to $\mathrm{CeO}_{2}$. After annealing at elevated temperatures, further Bragg peaks appear at lower $L$ values due to intermediate ceria phases with reduced oxygen content or cerium silicide. Starting at $850^{\circ} \mathrm{C}$ elongated features indicating a polycrystalline structure appear at $L=0.889,1.089,1.099$ and 1.128 in the reciprocal space mappings. These structures can not be unambiguously assigned to any cerium silicate $\left(\mathrm{CeSi}_{x} \mathrm{O}_{y}\right)$ or silicide $\left(\mathrm{CeSi}_{x}\right)$ phase.

CTR scans at $K_{\|}=0 \AA^{-1}$ of the $(00 L)$ CTR are performed for a detailed analysis of the appearing Bragg peaks with results shown in Fig. 9. The untreated sample shows the $\mathrm{CeO}_{2}(111)_{B}$ Bragg peak at $L=1.005$ corresponding to a vertical layer distance of $c_{\mathrm{CeO}_{2}}=3.120 \AA$ (bulk $c_{\mathrm{CeO}_{2}}=3.124 \AA$ ) next to the narrow $\operatorname{Si}(111)_{B}$ peak $(L=1)$. Furthermore, fringes of the praseodymia buffer layer are well discernible due to its very homogeneous thickness. These fringes do not change for all PDA treatments at temperatures below or equivalent to a temperature of $650^{\circ} \mathrm{C}$. For treatments at higher temperatures, the fringes are diminished due to a roughening of the buffer layer or a reaction between the ceria film and praseodymia buffer layer.

The Bragg peak corresponding to the praseodymia buffer layer is shifted to lower $L$ values than expected for hex$\operatorname{Pr}_{2} \mathrm{O}_{3}(0002)_{B}$ peak $(L=1.044)$ indicating an oxidation of the buffer layer during ceria growth. In addition, no Bragg peaks attributed to hex- $\operatorname{Pr}_{2} \mathrm{O}_{3}(0001)$ at $L=0.522$ and 1.566 were observed (not shown here). Thus, the praseodymia buffer layer has transformed to a cubic structure due to the additional oxygen content supplied by the ceria film. An accurate determi- nation of the position of the praseodymia Bragg peak is very difficult due to its weak intensity in comparison with the high intensity of the close $\mathrm{Si}(111)_{B}$ Bragg peak. An estimation can be made using a simulation within the kinematic diffraction theory. The results of such simulations point to a $L$ value between cub- $\operatorname{Pr}_{2} \mathrm{O}_{3}(222)_{B}(L=0.974)$ and $\operatorname{Pr}_{6} \mathrm{O}_{11}(111)_{B}(L=$ $0.997)$. Hence, we assume an oxidation of the buffer layer during growth in contrast to the growth of thinner ceria films on a hex $-\mathrm{Pr}_{2} \mathrm{O}_{3}(0001)$ buffer layer reported previously. ${ }^{8}$

After applying PDA temperatures of $650^{\circ} \mathrm{C}$ and $700^{\circ} \mathrm{C}$, further diffraction peaks appear at $L=0.982$ and $L=0.988$, respectively. Since the intermediate phases are based on the fluorite type $\mathrm{CeO}_{2}$ lattice with ordered oxygen vacancies, the stoichiometry $\mathrm{CeO}_{x}$ can be determined using the concept of the pseudo-cubic lattice parameter ${ }^{20,50}$ predicting the linear relationship

$$
x=-3.945 \AA^{-1} \cdot c+14.329
$$

between the stoichiometry parameter $x$ and the layer distance $c$ as shown in Fig. 10. Therefore, the peaks of the intermediate phases can be attributed to the $l\left(\mathrm{Ce}_{7} \mathrm{O}_{12}\right)$ and $\delta\left(\mathrm{Ce}_{11} \mathrm{O}_{20}\right)$ phases of ceria ${ }^{19}$ having the layer spacings of $c_{\mathrm{Ce}_{7} \mathrm{O}_{12}}=3.193$ $\AA$ and $c_{\mathrm{Ce}_{11} \mathrm{O}_{20}}=3.174 \AA$, respectively. The larger layer distances of the reduced phases results from the $\mathrm{Ce}^{4+} \rightarrow \mathrm{Ce}^{3+}$ transition yielding a larger ion radius. Note, the pseudocubic lattice parameter are based on the bulk structures of ceria and do not consider any strain effects which may appear in thin films. For the film studied here, the intensity of the $\mathrm{Ce}_{7} \mathrm{O}_{12}(111)_{B}$ and $\mathrm{Ce}_{11} \mathrm{O}_{20}(111)_{B}$ peaks increases with increasing PDA temperature.

Furthermore, the $\mathrm{Ce}_{7} \mathrm{O}_{12}(111)_{B}$ and $\mathrm{Ce}_{11} \mathrm{O}_{20}(111)_{B}$ peaks disappear when the XRD measurements are carried out at elevated temperatures and reappear after the sample is cooled 

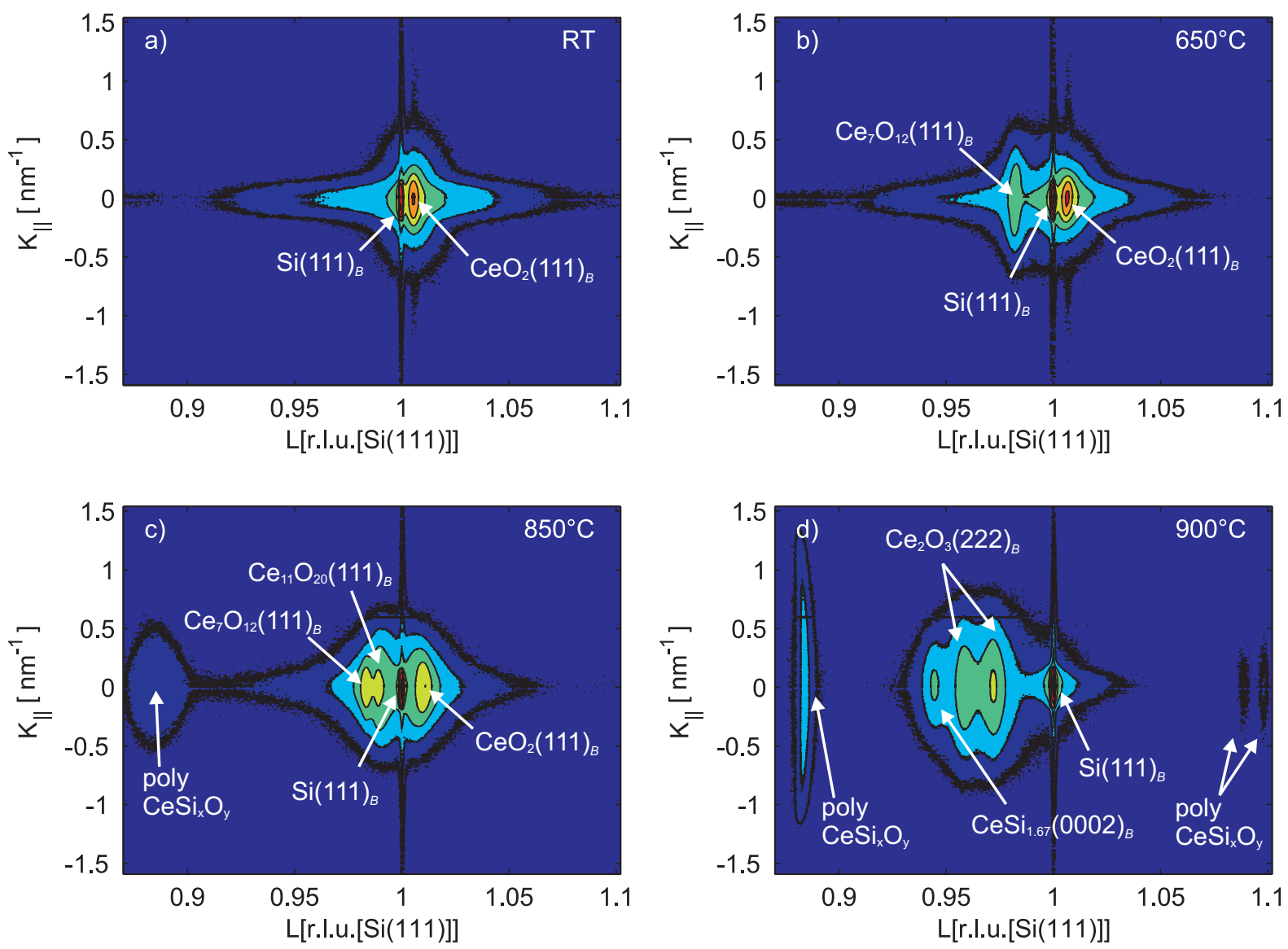

Fig. 8 Reciprocal space mappings close to the Si(111) Bragg peak obtained for annealing at different temperatures. The measurements are performed at RT. After annealing above $850^{\circ} \mathrm{C}$, elongated features pointing to a polycrystalline structure appear at $\mathrm{L}=0.89,1.09,1.10$.

(results not shown) while the $\mathrm{CeO}_{2}(111)_{B}$ peak does not vanish at these temperatures. Possible explanations for this temperature related behavior are a high Debye-Waller factor or an order-disorder transition due to the high mobility of lattice oxygen at high temperatures. The latter effect leads also to a disordered arrangement of oxygen vacancies and subsequent loss of the superstructure. On the other hand, the $\mathrm{CeO}_{2}(111)_{B}$ peak shifts to lower $L$ values (corresponding to higher layer distances) as expected due to thermal expansion when measured at elevated temperatures.

The reason for the smaller layer distance of the $\mathrm{CeO}_{2}$ film in comparison to the bulk structure (cf. Fig. 11 (a)) for low PDA temperatures is tensile lateral strain based on the lattice mismatch between the $\mathrm{CeO}_{2}$ (111) film and the praseodymia buffer layer ${ }^{8}$. With increasing PDA temperature the $\mathrm{CeO}_{2}(111)_{B}$ peak shifts to larger $L$ values (smaller layer distances) while the $\mathrm{Ce}_{7} \mathrm{O}_{12}(111)_{B}$ and $\mathrm{Ce}_{11} \mathrm{O}_{20}(111)_{B}$ peak positions do not change significantly (cf. Fig. 9 and Fig. 11 (a)). Assuming a tetragonally distorted film with biaxial in- plane strain $\Delta a$, the lateral layer distance $a$ of the appearing phases can be determined using the relation

$$
\frac{\Delta a}{a_{\mathrm{bulk}}}=-\frac{1-v}{2 v} \frac{\Delta c}{c_{\mathrm{bulk}}}
$$

as derived by Hashimoto et al. ${ }^{51}$, where $v \approx 0.3$ is the Poisson ratio of $\mathrm{CeO}_{2}{ }^{52}$. The $\mathrm{CeO}_{2}$ Poisson ratio is used for the calculations of all appearing phases since values of the Poisson ratio for the intermediate phases are not available in literature. The occurring error can be neglected since the structures of the intermediate phase are dominated by the cation sublattice which does not change significantly during reduction. The results for the lateral layer distance of the three phases is presented in Fig. 11 (b). With increasing PDA temperature, the calculated lateral layer distance of $\mathrm{CeO}_{2}$ shifts to higher values. Hence, the tensile strain of the remaining $\mathrm{CeO}_{2}(111)$ film is increased with higher temperatures. PDA treatments above $700^{\circ} \mathrm{C}$ do not change the lateral layer distances of the $\mathrm{Ce}_{7} \mathrm{O}_{12}$ and $\mathrm{Ce}_{11} \mathrm{O}_{20}$ phase. In comparison with the bulk values, the 


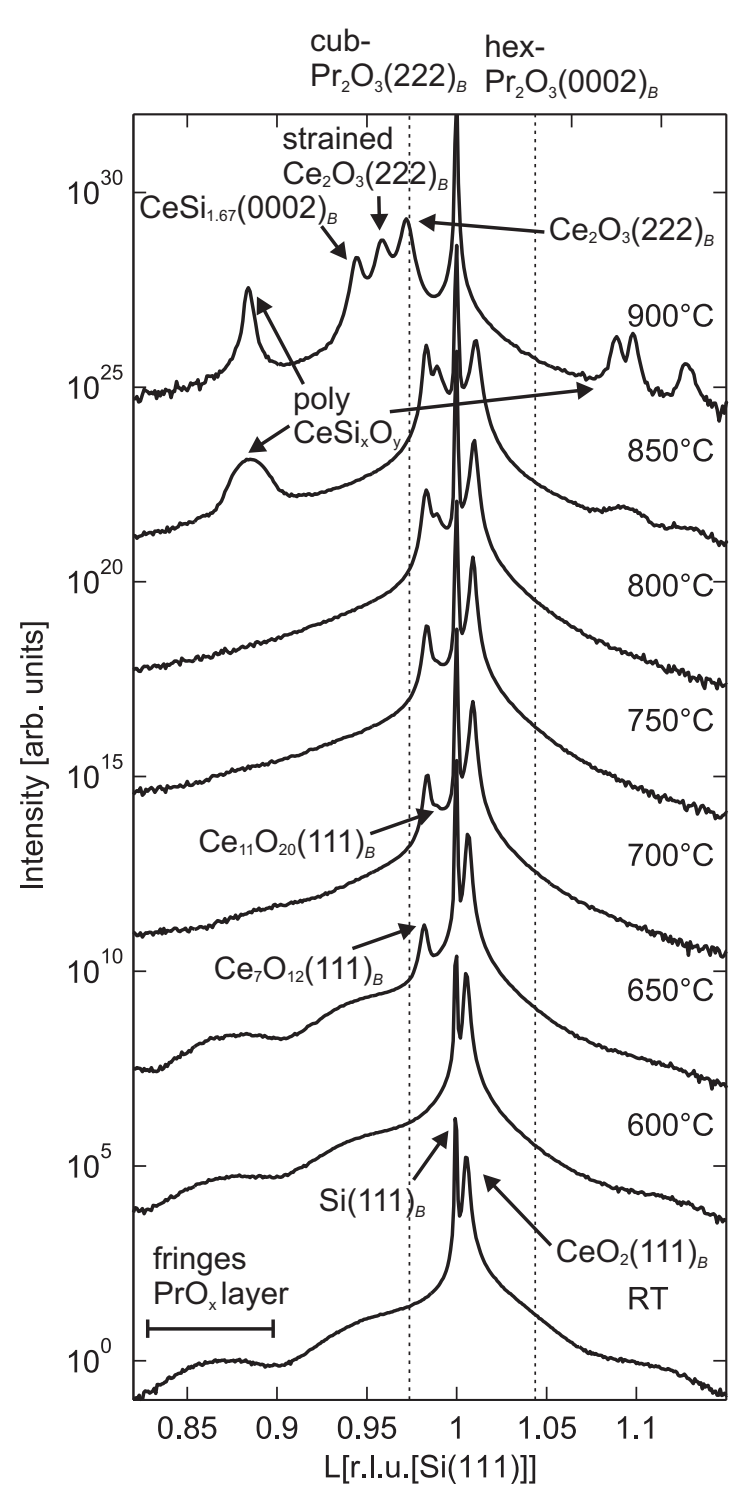

Fig. 9 Specular $(00 L)$ XRD scans close to the $\mathrm{Si}(111)_{\mathrm{B}}$ Bragg peak of the substrate. The samples are annealed at temperatures up to $900^{\circ} \mathrm{C}$ for $30 \mathrm{~min}$. After each temperature step, the samples are cooled to RT and the measurements are performed. The as grown sample shows only the $\mathrm{CeO}_{2}$ (111) peak next to the substrate. At temperatures above $600^{\circ} \mathrm{C}$ and $650^{\circ} \mathrm{C}$ peaks attributed to $\mathrm{Ce}_{7} \mathrm{O}_{2}(111)$ and $\mathrm{Ce}_{11} \mathrm{O}_{20}(111)$ appear, respectively. Thereafter, silicide and silicate peaks appear at temperatures above $800^{\circ} \mathrm{C}$. The observed fringes correspond to the underlying praseodymia buffer layer. The Bragg peak of the buffer layer seems shifted to $L$ values close to the cub- $\operatorname{Pr}_{2} \mathrm{O}_{3}(222)_{B}$ peak rather than the expected for hex- $\mathrm{Pr}_{2} \mathrm{O}_{3}(0002)_{B}$ peak (dashed lines). Therefore, an oxidation of the praseodymia layer during growth is assumed.
$\mathrm{Ce}_{7} \mathrm{O}_{12}$ exhibits strain similar to the $\mathrm{CeO}_{2}$ phase while the $\mathrm{Ce}_{11} \mathrm{O}_{20}$ phase is fully relaxed.

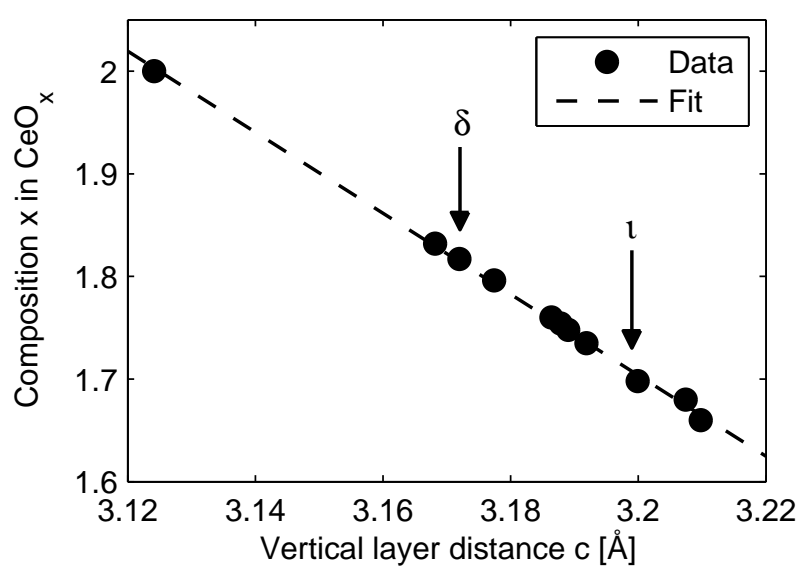

Fig. 10 Composition of the film expressed as the stoichiometry parameters $x$ plotted against the vertical layer distance $c$ according to the pseudo-cubic lattice parameters given by Ref. ${ }^{20,50}$.

After a PDA treatment at $900^{\circ} \mathrm{C}$, the three oxide peaks described above vanish and are replaced by peaks at $L=0.972$, $L=0.959$ and $L=0.944$ (cf. Fig. 9). The peak at $L=0.972$ corresponds to a vertical layer distance of $\mathrm{c}_{\mathrm{Ce}_{2} \mathrm{O}_{3}}=3.226 \AA$ and can be attributed to the cub- $\mathrm{Ce}_{2} \mathrm{O}_{3}(222)_{B}$ Bragg peak of the bulk bixbyite phase of $\mathrm{Ce}_{2} \mathrm{O}_{3}$ (bulk $\mathrm{c}_{\text {cub- } \mathrm{Ce}_{2} \mathrm{O}_{3}}=3.222 \AA$ ). Thus, the different oxide phases are transformed into the ceria phase of lowest oxygen content. In addition, no Bragg peaks of the hexagonal $\mathrm{Ce}_{2} \mathrm{O}_{3}$ phase $(L=0.518,1.036,1.554$, etc.) are observed. Thus, the cubic phase of $\mathrm{Ce}_{2} \mathrm{O}_{3}$ is formed exclusively.

The peak at $L=0.959$ corresponds to a layer distance of $\mathrm{c}_{\mathrm{Ce}_{2} \mathrm{O}_{3}(\mathrm{~s})}=3.270 \AA$ and can be attributed to a strained cub$\mathrm{Ce}_{2} \mathrm{O}_{3}$ film ${ }^{10}$. In comparison with the bulk value of $\mathrm{Ce}_{2} \mathrm{O}_{3}$, this vertical layer distance is $1.36 \%$ larger indicating a compressive lateral strain based on the lateral lattice mismatch of cub- $\mathrm{Ce}_{2} \mathrm{O}_{3}$ (111) with respect to $\mathrm{Si}(111)(+2.70 \%)$.

Furthermore, the peak at $L=0.944$ can not be assigned to any ceria phase and exhibits a larger periodicity $(L=$ $0.472,0.944,1.416$, etc. ), resulting in a layer distance of $c=6.642 \AA$. Taking into account the surface sensitive LEED and XPS measurements, we attribute this peak to the hex$\mathrm{CeSi}_{1.67}(0002)_{B}$ Bragg peak of the hexagonal $\mathrm{CeSi}_{1.67}$ phase proposed by Manke et al. ${ }^{42}$. 

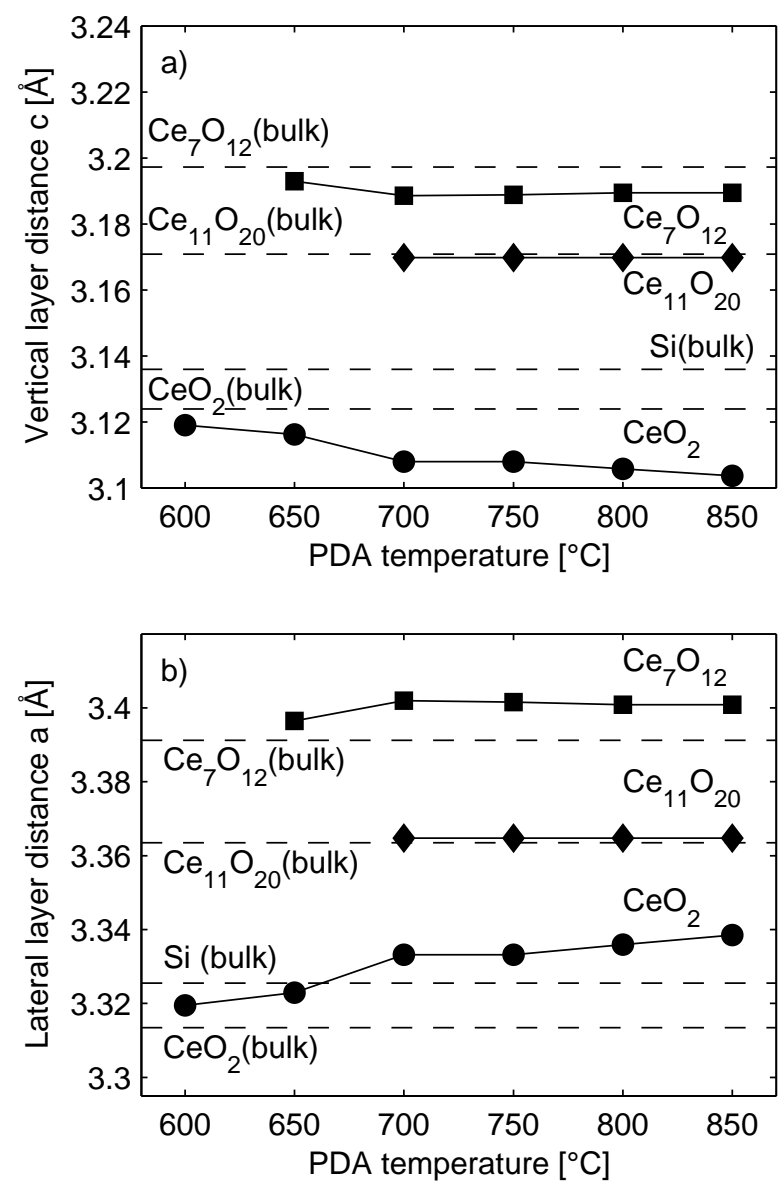

Fig. 11 (a) Vertical layer distance of the appearing ceria phases plotted against the PDA temperature. The stoichiometry of the different phases was determined by their pseudo-cubic lattice constant from Eq. 2. (b) Lateral layer distance determined from Eq. 3. The layer distances of the $\mathrm{CeO}_{2}$ and $\mathrm{Ce}_{7} \mathrm{O}_{12}$ differ from the bulk value indicating strained films while the $\mathrm{Ce}_{11} \mathrm{O}_{12}$ phase is fully relaxed.

\section{Discussion}

The SPA-LEED and XRD measurements reveal that the structure of the grown $\mathrm{CeO}_{2}$ (111) film and the praseodymia buffer layer is stable up to PDA temperatures of $650^{\circ} \mathrm{C}$. In contrast to these results the XPS data show a slight reduction of the near surface region indicating the formation of disordered oxygen vacancies in the low temperature region. At higher temperatures SPA-LEED and XPS measurements show a continuously reduction of the near surface region while the bulk sensitive XRD measurements reveal that not the entire film is reduced since the $\mathrm{CeO}_{2}(111)_{B}$ Bragg peak is detected up to PDA temperatures of $850^{\circ} \mathrm{C}$. In addition, a second intermediate phase $\left(\mathrm{Ce}_{11} \mathrm{O}_{20}\right)$ is formed at $700^{\circ} \mathrm{C}$ which exhibits a higher oxygen content as the earlier formed $\mathrm{Ce}_{7} \mathrm{O}_{12}$ phase. Since an increase of the oxygen content is not detected in the surface studies, we assume that this phase is formed either at the interface between the $\mathrm{Ce}_{7} \mathrm{O}_{12}$ and the $\mathrm{CeO}_{2}$ crystallites or at the interface region close to the silicon substrate. In the latter case, similar to the growth of the $\mathrm{CeO}_{2}(111)$ films ${ }^{8}$, oxygen has to be transported into the substrate resulting in the formation of amorphous $\mathrm{SiO}_{2}$ at the interface between film and substrate. We assume that a lower diffusion rate of oxygen into the substrate in comparison to the oxygen desorption at the surface is responsible for the formation of the $\mathrm{Ce}_{11} \mathrm{O}_{20}$ phase at the interface between film and substrate. This assumption is supported by the vanishing of the fringes due to the praseodymia buffer layer in the XRD measurements (cf. Fig. 9).This indicates an interface reaction, e.g. roughening of the praseodymia interface or an intermixing of the praseodymia and ceria films at temperatures above $650^{\circ} \mathrm{C}$. In addition, the tensile strain of the $\mathrm{CeO}_{2}$ film increases with higher annealing temperatures. Possible reasons for the increasing strain are the lateral lattice mismatch between $\mathrm{Ce}_{11} \mathrm{O}_{20}(111)$ and $\mathrm{CeO}_{2}(111)$ or the strong thermal expansion of the $\mathrm{CeO}_{2}(111)$ at elevated temperatures. Thus, more research has to be done to elucidate the role of the interface.

Comparing the diffraction measurements with the XPS results, a temperature offset for the formation of the $l$-phase $\left(\mathrm{Ce}_{7} \mathrm{O}_{12}\right)$ is observed. This phase is formed at $660^{\circ} \mathrm{C}$ if the sample is heated via resistive heating as done for the XRD and SPA-LEED experiments. On the contrary, the $l$-phase confirmed by conventional LEED setup is formed in the XPS experiments at $\approx 800^{\circ} \mathrm{C}$ when annealed via filament heating. We can exclude an experimental error in temperature control since the $\mathrm{Ce}_{2} \mathrm{O}_{3}$ phase with the lowest oxygen content and the silicide are formed at the same temperatures in both experimental setups. Thus, a possible explanation for the offset are the different cooling rates based on the experimental setup. Hence, we assume that for an annealing time of $30 \mathrm{~min}$ used in our experiments, the samples were not in the thermodynamical equilibrium. For the lower cooling rates (XPS experiments), oxygen from deeper layers of the oxide film diffuses to the surface since the oxide films is exposed to higher temperatures for longer times compared to the diffraction experiments. Hence, the formation of the superstructure received at high annealing temperatures is modified during the cooling process due to re-oxidation. We conclude that the cooling rate has a strong impact on the formation of the superstructures.

The XRD measurements show that polycrystalline $\mathrm{CeSi}_{x} \mathrm{O}_{y}$ or $\mathrm{CeSi}_{x}$ phases are formed after annealing at $850^{\circ} \mathrm{C}$ which can not be attributed to any known cerium silicate or silicide. This phase becomes more pronounced at $900^{\circ} \mathrm{C}$ and is also detected at the surface via SPA-LEED. In addition, a single crystalline cerium silicide $\left(\mathrm{CeSi}_{1.67}\right)$ is detected in the SPALEED and XRD studies.

The results from the XRD and SPA-LEED measurement 
clearly reveal the appearing $\mathrm{Ce}_{2} \mathrm{O}_{3}$ phase has a bixbyite structure (cub- $\mathrm{Ce}_{2} \mathrm{O}_{3}$ ). This is in contrast to studies of bulk single crystals where the hexagonal phase (hex- $\mathrm{Ce}_{2} \mathrm{O}_{3}$ ) is the most stable $^{53,54}$. Hence, the silicon substrate has a stabilization effect on the cub- $\mathrm{Ce}_{2} \mathrm{O}_{3}$ phase.

Furthermore, SPA-LEED measurements show a $(\sqrt{27} \times$ $\sqrt{27}) \mathrm{R} 30^{\circ}$ superstructure appearing in a very narrow region of PDA temperatures close to the temperature for the transition to cub- $\mathrm{Ce}_{2} \mathrm{O}_{3}$. Different to the $l$ phase, this diffraction pattern can not be attributed to the surface termination of any well known bulk phase of ceria stable at room temperature and Thus, we assume a film with stoichiometry close to $\mathrm{Ce}_{2} \mathrm{O}_{3}$ is stabilized at the near surface region.

Moreover, it should be mentioned that the color of the sample changes from purple (RT) to cyan $\left(890^{\circ} \mathrm{C}\right)$ during the PDA treatment. Above a PDA temperature of $900^{\circ} \mathrm{C}$ the sample turns mat gray due to the silicide formation (see also Ref. ${ }^{48}$ ). After a few minutes at a temperature of $930^{\circ} \mathrm{C}$ parts of the sample become metallic luster while the current needed for the resistive heating increases drastically.

\section{Conclusion}

In this study the influence of PDA on the structure and surface stoichiometry were investigated for a thin ceria film $(250 \mathrm{~nm})$ grown on a hex $-\mathrm{Pr}_{2} \mathrm{O}_{3}(0001) / \mathrm{Si}(111)$ system. It was shown that several crystalline phases with long range ordered oxygen vacancies can be stabilized which may be used for magnetic and catalytic applications in the future. Furthermore, it was revealed that the bulk and surface exhibit a different behavior during reduction. The XRD measurements reveal that higher oxidized phases are still present in the bulk of the film while the oxygen content at the surface is continuously reduced as shown by XPS and SPA-LEED. In addition, it is clearly shown that fully reduced ceria films $\left(\mathrm{Ce}_{2} \mathrm{O}_{3}\right)$ exhibit bixbyite structure if grown on $\mathrm{Si}(111)$. PDA treatments at very high temperatures lead to the formation of polycrystalline silicate and crystalline silicide.

\section{Acknowledgment}

The authors gratefully acknowledge support by the Deutsche Forschungsgemeinschaft (DFG) via grant no. WO533/16-1, RE 1186/12-1, BA 1710/17-1 and SCHR1123/4-1 and by the COST Action CM1104. We like to thank W. Caliebe for beamline support during synchrotron experiments carried out at HASYLAB/DESY.

\section{References}

1 A. Trovarelli, Catal. Rev. - Sci. Eng., 1996, 38, 439.
2 A. F. Diwell, R. R. Rajaram, H. A. Shaw, T. J. Treux, The role of ceria in three-way catalysts, in Catalysis Automotive Pollution Control, Vol. 71 (Ed.: A. Cruq), Elsevier, Amsterdam, 1991.

3 G. A. Deluga, J. R. Salge, L. D. Schmidt, X. E. Verykios, Science, 2004, 303, 993.

4 S. Torbrügge, M. Reichling, A. Ishiyama, S. Morita, and O. Custance, Phys. Rev. Lett., 2007, 99, 056101.

5 T. Campbell, Surf. Sci. Rep.,1997, 27, 1.

6 R. Henry, Surf. Sci. Rep., 1998, 31, 231.

7 M. Bäumer, and H.-J. Freund, Prog. Surf. Sci., 1999, 61, 127.

8 M. H. Zoellner, J. Dabrowski, P. Zaumseil, A. Giussani, M. A. Schubert, G. Lupina, H. Wilkens, J. Wollschläger, M. Reichling, M. Bäumer, and T. Schroeder, Phys. Rev. B, 2012, 85, 035302.

9 H. H. Pieper, C. Derks, M. H. Zoellner, R. Olbrich, L. Tröger, T. Schroeder, M. Neumann, and M. Reichling, Phys. Chem. Chem. Phys., 2012, 14, 15361.

10 J. I. Flege, B. Kaemena, S. Gevers, F. Bertram, T. Wilkens, D. Bruns, J. Bätjer, T. Schmidt, J. Wollschläger, and J. Falta, Phys. Rev. B, 2011, 84, 235418.

11 T. Inoue, Y. Yamamoto, S. Koyama, S. Suzuki, and Y. Ueda, Appl. Phys. Lett., 1990, 56, 1332.

12 J. Zarraga-Colina, R.M. Nix, and H. Weiss, Surf. Sci., 2004 563, L251.

13 R. K. Singhal, P. Kumari, A. Samariya, S. Kumar, S. C. Sharma, Y. T. Xing, and E. Saitovitch, Appl. Phys. Lett., 2010, 97, 172503.

14 R. K. Singhal, P. Kumari, S. Kumar, S. N. Dolia, Y. T. Xing, M. Alzamora, U. P. Deshpande, T. Shripathi, and E. Saitovitch, J. Phys. D: Appl. Phys., 2011, 44, 165002.

15 M. Chandra Dimri, H. Khanduri, H. Kooskora, J. Subbi, I. Heinmaa, A. Mere, J. Krustok, and R. Stern, Phys. Status Solidi A, 2012, 209, 353.

16 V. Fernandes, R. J. O. Mossanek, P. Schio, J. J. Klein, A. J. A. de Oliveira, W. A. Ortiz, N. Mattoso, J. Varalda, W. H. Schreiner, M. Abbate, and D. H. Mosca, Phys. Rev. B, 2009, 80, 035202.

17 Y. Q. Song, H. W. Zhang, Q. Y. Wen, Hao Zhu, and J. Q. Xiao, J. Appl. Phys., 2007, 102, 043912.

18 X. Han, J. Lee, and H. I. Yoo, Phys. Rev. B, 2009, 79, 100403.

19 Subramanian P.R.: "Ce-O (Cerium-Oxygen)", Binary Alloy Phase Diagrams, edited by T. B. Massalski, 2nd ed. (ASM International, Materials Park, 1990), Vol. 2, pp. 1089-1091

20 E.A. Kümmerle, and G. Heger, J. Solid State Chem., 1999, 147, 485.

21 D. J. M. Bevan, J. Inorg. Nucl. Chem., 1955, 1, 49.

22 H. Wilkens, O. Schuckmann, R. Oelke, S. Gevers, A. Schaefer, M. Bäumer, M. H. Zoellner, T. Schroeder, and J. Wollschläger, Appl. Phys. Lett., 2013, 102, 111602.

23 A. Schaefer, T. Schroeder, G. Lupina, Y. Borchert, J. Dabrowski, C. Wenger, and M. Bäumer, Surf. Sci., 2007, 601, 1473.

24 T. Schroeder, T.-L. Lee, L. Libralesso, I. Joumard, J. Zegenhagen, P. Zaumseil, C. Wenger, G. Lupina, G. Lippert, J. Dabrowski, and H.-J. Müssig, J. Appl. Phys., 2005, 97, 074906.

25 F. Bertram, C. Deiter, K. Pflaum and O. H. Seeck, Rev. Sci. Instrum., 2012, 83, 083904

26 A. Schaefer, S. Gevers, V. Zielasek, T. Schroeder, J. Falta, J. Wollschläger, and M. Bäumer, J. Chem. Phys., 2011, 134, 054701.

27 J.P. Holgado, G. Munuera, J.P. Espinós, A.R. González-Elipe, Appl. Surf. Sci., 2000, 158, 164

28 D.R. Mullins, S.H. Overbury, D.R. Huntley, Surf. Sci., 1998, 409307.

29 W. Xiao, Q. Guo, E.G. Wang, Chem. Phys. Lett., 2003, 368, 527.

30 E. Paparazzo, G. M. Ingo, and N. Zacchetti, J. Vac. Sci. Technol. A, 1991, 9, 1416.

31 M.L. Trudeau, A. Tschope, and J.Y. Ying, Surf. Interface Anal., 1995 23, 219.

32 J. P. Holgado, R. Alvarez, and G. Munuera, Appl. Surf. Sci., 2000, 161, 301.

33 A. Allahgholi, J. I. Flege, S. Thiess, W. Drube, and J. Falta in preparation (2013). 
34 E. J. Preisler, O. J. Marsh, R. A. Beach, and T. C. McGill, J. Vac. Sci. Technol. B, 2001, 19, 1611.

35 A. Kotani, and H. Ogasawara, J. Electron Spectrosc. Relat. Phenom., 1992, 60, 257.

36 J. C. Fuggle, F. U. Hillebrecht, Z. Zolnierek, R. Lässer, Ch. Freiburg, O. Gunnarsson, and K. Schönhammer, Phys. Rev. B, 1983, 27, 7330.

37 E. Wuilloud, H. R. Moser, W.-D. Schneider, and Y. Baer, Phys. Rev. B, 1983, 28, 7354.

38 G. Praline, B. E. Koel, R. L. Hance, H.-I Lee, and J. M. White, J. Electron Spectrosc. Relat. Phenom., 1980, 21, 17.

39 A. Laachir, V. Perrichon, A. Badri, J. Lamotte, E. Catherine, J. C. Lavalley, J. El Fallah, L. Hilaire, F. Le Normand, E. Quéméré, G. N. Sauvion, and O. Touret, J. Chem. Soc. Faraday Trans., 1991, 97, 1601.

40 S. Gevers, T. Weisemoeller, B. Zimmermann, F. Bertram, C. Deiter, J. Wollschläger, J. Phys.: Condens. Matter, 2009, 21, 175408.

41 S. Gevers, T. Weisemoeller, B. Zimmermann, C. Deiter, J. Wollschläger, phys. stat. sol. C (c), 2010, 7, 292.

42 I. Manke, H. J. Wen, A. Bauer, M. Dähne-Prietsch, and G. Kaindl, J. Vac. Sci. Technol. B, 1995, 13, 1657.
43 A. Fujimori, M. Grioni, J. J. Joyce, J. H. Weaver, Phys. Rev. B, 1987, 36, 1075.

44 M. Henzler, Appl. Phys. A, 1984, 34, 205.

45 M. Henzler, Surf. Rev. Lett., 1997, 4, 489.

46 T.-M. Lu, and M. G. Lagally, Surf. Sci., 1982 , 120, 47.

47 J. Wollschläger, Surf. Sci., 1995, 328, 3.

48 R. Olbrich, H. H. Pieper, R. Oelke, H. Wilkens, J. Wollschläger, M. H. Zoellner, T. Schroeder, and M. Reichling, in preparation 2013.

49 S. Torbrügge, M. Cranney, and M. Reichling, Appl. Phys. Lett., 2008, 93, 073112

50 S. P. Ray, A. S. Nowick, and D. E. Cox, J. Solid State Chem., 1975, 15, 344.

51 S. Hashimoto, J. L. Peng, W. M. Gibson, L. J. Schowalter, and R. W. Fathauer, Appl. Phys. Lett., 1985, 47, 1071.

52 V. Kanchana, G. Vaitheeswaran, A. Svane, and A. Delin, J. Phys.: Condens. Matter, 2006, 18, 9615.

53 J. L. F. Da Silva, Phys. Rev. B, 2007, 76, 193108.

54 H. Bärnighausen and G. Schiller, J. Less-Common Met., 1985, 110, 385. 